\title{
Editorial
}

\section{Sustainable Cultural Management in the 21st Century}

\author{
Łukasz Wróblewski $^{1, *(1)}$, Ana Gaio ${ }^{2}$ and Ellen Rosewall $^{3}$ \\ 1 Research Institute on Territorial and Inter-Organizational Cooperation, University of Dąbrowa Górnicza, \\ Cieplaka 1c, 41-300 Dąbrowa Górnicza, Poland \\ 2 Department of Sociology, City, University of London, Northampton Square, London EC1V 0HB, UK \\ 3 Department of Arts Management, University of Wisconsin-Green Bay, 2420 Nicolet Dr., \\ Green Bay, WI 54311, USA \\ * Correspondence: lwroblewski@wsb.edu.pl; Tel.: +48-692-344-057
}

Received: 23 August 2019; Accepted: 23 August 2019; Published: 27 August 2019

The connections between culture and sustainability have been in the public agenda since the 20th century. However, whilst global sustainability programmes at international institutional levels are yet to recognise the role of culture in its sustainability policies, the bid (albeit failed) in the early 2000s to formally add 'culture' to the trilogy of sustainability pillars (economic, social and environmental) mobilised a new discourse for the reframing of cultural policy narrative, which in turn urged a reassessment of methods of cultural management reflecting the same concerns among the sector's grassroots. The idea of sustainability and culture working together and their envisioned role in future-proofing society and human development captured the imagination of cultural commentators, policy makers and practitioners alike, keen to fulfil these principles 'out there'; in cultural organizations and events mega and small, in cities and regions, local and global. The papers in this Special Issue reflect this appeal.

They also echo the semantic journeys and complexities inherent in the concepts of sustainability and culture and their interface. The definition of sustainability as a paradigm within which to interpret biological and social interdependencies [1] contrasts with more descriptive temporal and spatial accounts but provides an important clue about the (eco) systemic nature of this concept and its contingency on the 'interdependency' of systems' elements, which is what might need to be 'managed'. The subsequent application of the term to processes of development [1] shifted the emphasis from sustainability to sustainable development, lending a processual connotation, if not tangibility, to the sustainability discourse. Along similar lines, the application of these concepts to business (as to many other disciplines), acknowledged its embeddedness, in other words, its interdependencies with society and the environment and stressed the relevance of the sustainability vision to business (and therefore) to management, codified in the 'triple bottom line' framework [2]. Hence, sustainable (business) management is concerned with attaining, amongst other things, an economically, socially, and environmentally responsible society and in doing so with engaging in and securing sustainable development. More specifically, a system can also be seen from an internal, organizational perspective and the resource-based perspective that is common to sustainability and management, often focusing on the economic 'pillar' and expressing a concern for economic viability, is also studied as an organizational subset of sustainable management.

Culture is an equally complex and multifaceted term, commonly evoked as the broad and inclusive arts and culture sector and as ways of life and collective identities. At the height of the international debate, a decade or so ago, over the value of culture and the (perceived development) value of a then emergent creative economy (North and South, East and West), it was a matter of time before the cultural and sustainability policy agendas intersected. Various theories have expounded the relationship between culture and sustainability and, similarly, sustainable development [1,3-5], though these invariably postulate the use of culture, its manifestations or their operation, as an instrument, 
as a subject of sustainability. Culture in its various expressions resonates on many levels of people's everyday lives, which makes it a perfect vehicle for social and economic mobilisation [6]. Less explored in the extant literature, however, is an-other ontology of culture within the scope of sustainability in which culture (in any of its dimensions) is assumed to be the object-not the subject-of sustainable practice. This applies to culture as a way of life as to cultural undertakings, a museum, an art gallery, a film production company, which like any other concern interact with society and the environment as producers, consumers, social and economic actors. Still, these ultimately operate in the pursuit of their inherent cultural, prosocial mission, collectively expressing and transforming society as aesthetic innovators, as curators of cultural memory, as community engagement cultivators, as hubs and outlets for cultural and creative expression. On this premise, sustainable cultural management might be aptly described in terms of the deployment of responsible management practices and policies with the goal to fulfil these outcomes and, more generally, to sustain a thriving culture.

The concept of sustainability offers a new framework for redesigning cultural policies and revisiting cultural management methods through a comprehensive approach that encompasses care for the environment, develops practices for sound management of public resources and brings the concept of social responsibility to the forefront [7]. This concept requires an innovative approach not only to the cultural offer and the provision of services in the field of culture, but also to the formation of long-term relations with interested parties and investments in local communities. Cultural organizations that introduce innovations in line with the sustainable management concept must constantly improve their management systems, processes and tools, whilst skillfully managing their relations with various interest groups. This consequently leads to the provision of value which combines both the economic and social aspects $[8,9]$.

Given this, the Special Issue on Sustainable Cultural Management fulfils a considerable gap in the literature, and attempts to illuminate this broad and tricky field in an interesting manner. The publication consists of fifteen separate articles. The geographical variety of individual cases is one of the greatest strengths of the publication. Individual articles deal with different aspects of sustainable cultural management from a variety of countries, including Poland, Czech Republic, Romania, Italy, Spain, and Taiwan, as well as China and USA. Although the structure of the publication is not a traditional one, it finds its rationale and contributes to the aim of the overall project. The theoretical and empirical components of the publications are well balanced and the Special Issue on Sustainable Cultural Management provides ample and interesting new findings. Well-referenced bibliographic resources and their own research underpin the contents of the publication.

In the first article, titled Sustainable Management of the Offer of Cultural Institutions in the Cross-Border Market for Cultural Services-Barriers and Conditions, by using different notions of the market, a new definition of a cross-border market for cultural services was presented. Authors based this on the example town divided by a border-Cieszyn (Poland) and Český Těšín (Czech Republic) indicated by barriers in the town, which made it difficult for the residents to benefit from the cultural offer that was available on the other side of the border. The results of the authors' research proved that despite numerous cross-border Czech-Polish projects carried out by cultural institutions, language, information, economical, and psychological barriers limited the full implementation and application of the concept of sustainable cultural management in the town divided by a border.

The second article written by Łukasz Wróblewski and Zdzisława Dacko-Pikiewicz concentrates on the problems of sustainable consumer behaviour in the market of cultural services in Central European countries. In this article, most of the attention was devoted to the culture service, customers' choice of means of transport used on the way to a cultural event. In the article, it was proven that despite various legal regulations conducive to sustainable consumption in Poland, the majority of Polish consumers of cultural services in the analysed area of consumer behaviour still do not follow this concept.

The next article, authored by Pier Luigi Sacco, Guido Ferilli, and Giorgio Tavano Blessi presents a new conceptual framework to analyze the evolution of the relationship between cultural production and different forms of economic and social value creation in terms of three alternative socio-technical 
regimes that have emerged over time. Authors explain how, with the emergence of the Culture 3.0 regime characterized by novel forms of active cultural participation, the distinction between producers and users of cultural and creative contents is increasingly blurred, new channels of social and economic value creation through cultural participation acquire increasing importance. Authors noticed also that, the Culture 3.0 perspective is finding space in the EU's strategic thinking on the role of culture in future policies. However, having to face the urgencies posed by the many economic and social criticalities of today, there is a constant risk that the EU marginalizes in practice the role of cultural policy rather than upgrading it to the new level, and that would be a sign that there is still a significant gap in terms of strategic vision and conceptual awareness of the revolutionary implications of Culture 3.0.

Article four, prepared by Łukasz Wróblewski, Katarzyna Bilińska-Reformat, and Mateusz Grzesiak, focuses on the sustainable activity of cultural service consumers of social media users. The article presents the results of a survey that was conducted in 2018 on a group of 1021 consumers of cultural services, who at the same time regularly used social media. The statistical analysis carried out and the research results obtained proved that the activity of consumers of cultural institutions on the Internet, and in particular, on social media, stimulated the brand's awareness/associations with the brand of a cultural institution and the perception of its quality.

The fifth article, entitled Moving Urban Sculptures towards Sustainability: The Urban Sculpture Planning System in China, prepared by Zhe Liu, Pieter Uyttenhove, and Xin Zheng, is based on the review of more than 100 articles, plans, and government documents, and findings obtained from semi-structured interviews. The article argues that urban planning strategies and policies have been conceived as strategic instruments by the Chinese municipal governments to realize sustainable development of urban sculptures. Findings of authors are very valuable, because they would enrich knowledge on geographic studies of public art planning through the contextualized analysis of a Chinese urban sculpture planning system.

A further article prepared by Hailing Wang, Libiao Bai, Ning Huang, Qiang Du, and Tingting Zhang depicts culture as a base in new kind of management from the social aspect, termed as Social Project Culture (SPC). Authors noticed that SPC can promote sustainable development and improve the management level and efficiency of organizations by promoting management by project application across society. In addition, it can reduce the communication barriers in different enterprises and improve the success rate of cooperation. For managers, SPC can reduce the management difficulties caused by different cultures, outdated management, and changing environments. For government, it can indirectly promote the economic development of society by prompting the prosperity of enterprises and organizations.

Article seven, prepared by Gail Markle, focuses on an understanding, pro-environmental behavior in the United States. The author using insights from grid-group cultural theory and cognitive sociology, designed a mixed-methods study, which examined the factors that influenced pro-environmental behavior among a nationally representative U.S. sample $(n=395)$. Qualitative results indicated that individuals develop culturally specific environmental socio-cognitive schemas, which they use to assign meaning to the environment and guide their environmentally significant behavior. Quantitative results indicate cultural orientation, pro-environmental orientation, environment identity, and environmental influence predict pro-environmental behavior. According to the opinion of the author, applying these combined theoretical perspectives to the social problem of environmental degradation could facilitate the development of targeted strategies for bringing about impactful behavioral change. This study is significant because synthesizing grid-group cultural theory and cognitive sociology enables us to better understand obstacles to the individual and collective performance of efficacious pro-environmental behavior.

The next article, entitled Sustainable Management of Contemporary Art Galleries: A Delphi Survey for the Spanish Art Market, written by Alicia Mateos-Ronco and Nieves Peiró Torralba, focuses on art galleries, which are the most influential intermediaries in the Spanish primary contemporary fine-art market and perform a role that goes beyond the mere distribution of works of art. This paper develops 
and applies a prospective methodology based on the information compiled by twenty-five experts to identify and evaluate the factors that determine the current situation and future outlook for Spanish contemporary art galleries. The results show, that the survival of these organizations will depend on their ability to adapt to the changing conditions of the economic environment; reactivating and internationalizing demand and redirecting their business model towards sustainable management by implementing appropriate business management models and techniques.

Article nine, titled Filmmaking and Crowdfunding: A Right Match? written by Mina Fanea-Ivanovici, complements the other parts of the publication in an appropriate manner. In this study, the author raises the question of identifying alternative financial resources for filmmakers in Romania. The main aim of the article was to study Romanian filmmakers' attitudes towards crowdfunding and its perceived suitability for financing film projects. The author based on the results of the study, argued that regulating crowdfunding in Romania was a desired and necessary step in its development. Such regulation does not primarily regard the existing forms of crowdfunding in Romania-reward-based and donation-based-which can still be used without any intervention. However, regulation would allow the existence and operation of crowdfunding platforms in the more advanced forms of this financing instrument: equity-based crowdfunding, lending-based crowdfunding, invoice trading and hybrid forms.

The tenth article written by Izabela Luiza Pop, Anca Borza, Anuta Buiga, Diana Ighian, and Rita Toader concentrates on the achieving of cultural sustainability in museums. The main aim of the paper was to develop econometric models that explained the influence of heritage exposure; environmental behavior; openness to the public; and effectiveness and performance in collecting, preserving, and researching the cultural heritage. To achieve this goal authors conducted survey research in 86 Romanian museums. The findings of the study indicated that museums' effectiveness and performance, openness to the public, and heritage exposure have a positive impact on cultural sustainability.

A further article prepared by Yi-De Liu, entitled Event and Sustainable Culture-Led Regeneration: Lessons from the 2008 European Capital of Culture, Liverpool is based on long-term and multi-faceted data. The study aimed to contribute to the debate on urban cultural policy and management by answering two research questions: What are the key success factors for sustainable culture-led regeneration? How can cities strike a balance between the dilemmas of culture-led regeneration? The author's research revealed that incorporating events in a city's long-term regeneration trajectory, continued support and enhancement of local cultural processes and structures, and highlighting community involvement and development were major factors to ensuring the cultural sustainability of the event.

The next study written by Yongchun Yang, Yan Sun, and Weiwei Wang concentrates on the research on Tibetan folk's contemporary Tibetan cultural adaptive differences and its influencing factors. Authors noticed that the Tibetans' cultural adaptive strategies tended toward integration of modern and traditional culture in the affective, behavioral, and cognitive dimensions, whose characteristics were especially represented in the behavioral dimension. This represents a genuinely useful enrichment of the publication and contributes to its versatile nature as it concerns both functional and geographical aspects of the culture.

The main purpose of article thirteen written by Jan Suchacek was to analyze and evaluate cultural and creative industries in Ostrava, the third largest city of the country that at the same time constituted a typical representative of old industrial urban fabrics in the Czech Republic. In this article special attention was devoted to the emerging cultural clusters that appeared to be indispensable in terms of sustainable cultural management. The results of the author's research indicated that the paths towards cultural management sustainability could differ substantially from recipes, which were well-proven in leading developed territories. The author's analysis confirmed some developmental effects evoked by the concentration of cultural industries and cultural clusters in Ostrava could be identified, but genuine qualitative transformation towards a more cultural and sustainable milieu in Ostrava undoubtedly requires more time. 
Article fourteen, titled, The Role of Marketing in Cultural Institutions in the Context of Assumptions of Sustainable Development Concept-A Polish Case Study, prepared by Magdalena Sobocińska, was based on literature studies and the results of empirical and quantitative research that was conducted on a sample of 451 people managing cultural institutions in Poland. An analysis of research results showed that consumers of culture were ranked first as recipients of targeted actions conducted by cultural institutions. An increase in the diversity of cultural offers, including the concept of sustainable development, emerged as a factor stimulating the development of the culture market, being closely related to growth of the quality of cultural offer in Poland.

In the final paper, The Sustainable Development of Social Media Contents: An Analysis of Concrete and Abstract Information on Cultural and Creative Institutions with "Artist" and "Ordinary People" Positioning, Yulin Chen used social media content discovery technology to analyze 9529 image posts. The results showed that for abstract themes, for example, art or design, people could be more easily guided by information with the help of images, which stimulated positive emotions, resulting in more actual engagement behavior, including posting and sharing.

These constructs are common threads running through (implicitly in cases) this Issue's articles. In this context, the papers that follow expose and interrogate a varied range of problematics and critical questions in the relationship between sustainability and culture and how they intersect, engaging with them at a variety of levels, from the international to the local, from culture to cultural organizations, from policy to management. In summary, the presented Special Issue on Sustainable Cultural Management is of pivotal importance in the field of cultural management, as it reflects both the trans-disciplinary nature of the field, as well as the spectrum of cultural individuality caused by geographical differentiation. The publication covers a wide selection of issues related to sustainable cultural management, which means that it can be recommended to a varied audience. First of all, it can be recommended to managers experienced in cultural management, where success is measured more by the degree of mission accomplishment and the social benefits achieved rather than by profit. Another group are the employees of cultural organizations who want to improve their knowledge about sustainable cultural management. Our Special Issue can also be recommended to artists, researchers, students, state and local government employees, founders and patrons of art, and all those who want to understand the importance of sustainable cultural management. As the editors of this Special Issue, we see this breadth of research and exploration into sustainable cultural management as its key contribution to current perspectives in the field.

Conflicts of Interest: The authors declare no conflicts of interest.

\section{References}

1. Throsby, D. Culturally sustainable development: Theoretical concept or practical policy instrument? Int. J. Cult. Policy 2017, 23, 133-147. [CrossRef]

2. Elkington, J. Towards the Sustainable Corporation: Win-Win-Win Business Strategies for Sustainable Development. Calif. Manag. Rev. 1994, 36, 90-100. [CrossRef]

3. Dessein, J.; Soini, K.; Fairclough, G.; and Horlings, L.; Battaglini, E.; Birkeland, I.; Duxbury, N. Culture in, for and as Sustainable Development; Conclusions from the COST Action IS1007 Investigating Cultural Sustainability; University of Jyväskylä: Jyväskylä, Finland, 2015.

4. Kangas, A.; Duxbury, N.; De Beukelaer, C. Introduction: Cultural policies for sustainable development. Int. J. Cult. Policy 2017, 23, 129-132. [CrossRef]

5. Portolés, J.B.; Dragićevic Šešić, M. Cultural rights and their contribution to sustainable development: Implications for cultural policy. Int. J. Cult. Policy 2017, 23, 159-173. [CrossRef]

6. Pratt, A.C. Creative Industries and Development: Culture in development, or the cultures of development? In The Oxford Handbook of Creative Industries; Jones, C., Lorenzen, M., Sapsed, J., Eds.; Oxford University Press: Oxford, UK, 2015; pp. 503-515.

7. Liu, J. Measuring the value and impact of culture: Why and how? A literature review of academic and practical works. Cult. Manag. Sci. Educ. 2018, 2, 9-30. [CrossRef] 
8. Dragićević Šešić, M.; Stefanović, M. Leadership styles and values: The case of independent cultural organizations. Cult. Manag. Sci. Educ. 2017, 1, 29-37. [CrossRef]

9. Bernstein, J. Building audiences frequency and loyalty. Forum Sci. Oecon. 2017, 5, 5-15.

(C) 2019 by the authors. Licensee MDPI, Basel, Switzerland. This article is an open access article distributed under the terms and conditions of the Creative Commons Attribution (CC BY) license (http://creativecommons.org/licenses/by/4.0/). 